4 - ORIGINAL ARTICLE

EXPERIMENTAL UROLOGY

\title{
Decompressive fasciotomy in testicular torsion of the spermatic cord in rats ${ }^{1}$
}

\author{
Isabela Passos Pereira Quintaes ${ }^{\mathrm{I}}$, Edson Samesima Tatsuo ${ }^{\mathrm{II}}$, Danilo Nagib Salomão Paulo ${ }^{\mathrm{III}}$, Carlos Musso ${ }^{\mathrm{IV}}$, Paulo César Ribeiro \\ Boasquevisque \\ ${ }^{I}$ Master, Surgery Department. Espirito Santo Federal University (UFES), Brazil. Conception, design and scientific content of the study, manuscript \\ writing. \\ "Full Professor, Surgery Department, Minas Gerais Federal University (UFMG), Brazil. Conception, design and scientific content of the study.

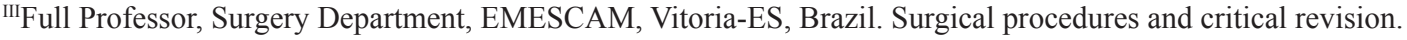

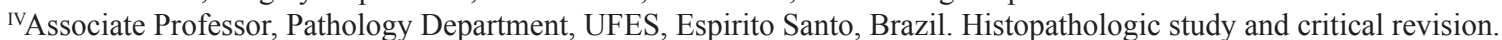 \\ v Master, Surgery Department, UFES, Espirito Santo, Brazil. Surgical procedures.
}

\section{ABSTRACT}

PURPOSE: To evaluate the effect of decompression fasciotomy on testes undergoing torsion of the spermatic cord.

METHODS: Spermatic cord torsion was induced in 40 Wistar testes for six and 12 hours. At the time of distortion, decompression fasciotomy was performed on half of the animals. After 42 days, the testicles were examined both macroscopically and microscopically. A non-parametric Mann- Whitney U- test was used for statistical analysis. The results were considered significant at $\mathrm{p} \leq 0.05$.

RESULTS: Testicular weight; volume and degree of histological alterations were evaluated. When the groups without and with fasciotomy were compared, a 12-hour torsion subgroup in the fasciotomy group was noted to present larger volume, heavier weight and superior histological classification when compared with the 12-hour subgroup in the without fasciotomy group. No differences between the two groups after six hours of torsion were found. No significant changes were noticed in the contralateral testis.

CONCLUSIONS: Testicular fasciotomy (decompression) benefited the macroscopic and histological aspects of the testicles undergoing cord torsion for a 12-hour period. These results demonstrate the role played by compartment syndrome in the pathophysiology of spermatic cord torsion and the need for decompression.

Key words: Spermatic Cord Torsion. Compartment Syndromes. Surgery. Animal Experimentation. Rats 


\section{Introduction}

Spermatic cord torsion results from abnormal testicular rotation about the longitudinal axis of a testicle. This problem occurs in approximately one in 4000 men under age of $25^{1}$. Spermatic cord torsion accounts for $25 \%$ to $30 \%$ of acute scrotum ${ }^{1,2}$. Important cause of male infertility over $25 \%$ of testes considered viable during surgical exploration may develop atrofia $\mathrm{a}^{2,3}$.

Acute compartment syndrome, most commonly seen following trauma of the extremities, is defined as a condition in which increased pressure within a limited space compromises the tissue circulation and function. Flow interruption in a traumatized capillary bed is the end result of tissue damage in the pathophysiology of compartment syndrome ${ }^{3,4}$.

Currently, existing clinical and experimental data suggest that unilateral testicular ischemia induced by torsion of the spermatic cord results in specific and irreversible changes in the histology of the ipsilateral and contralateral testis; the damage is proportional to the duration of the ischemia. These irreversible changes can be correlated with a subsequent reduction in fertility ${ }^{5}$.

Spermatic cord torsion results in progressive testicular venous occlusion, interstitial edema, arterial occlusion and subsequent parenchymal ischemia. Parenchymal hyperemia and further edema occur after detorsion. The inflammatory response which is induced by reperfusion is largely responsible for the testicular damage. The major consequence of this response is the excessive generation of reactive oxygen substances and oxidative stress. The overproduction of free radicals is a mediator of cellular $\operatorname{apoptosis}^{6,7}$.

These changes may create a "closed compartment syndrome" with the tunica albuginea of the testis resulting in further parenchymal damage.

This study was designed to determine if testicular fasciotomy could influence the macroscopic and histologic changes produced in the testis by spermatic cord torsion.

\section{Methods}

Approved by the Research Ethics Committee from the Federal University of Minas Gerais (UFMG), School of Medicine.

Forty male Wistar rats, aged between 60 and 80 days and weighing between 260 and $430 \mathrm{~g}$ were used.

The rats were randomly assigned to one of two groups with 16 rats in each group.

In addition eight rats were assigned to a third sham group. The group details are as follows:
Rats without fasciotomy (WOF group $n=16$ ) were divided into two subgroups, with eight rats undergoing right testis torsion for six hours, followed by detorsion without fasciotomy (WOF6) and eight rats undergoing right testis torsion for 12 hours, followed by detorsion without fasciotomy (WOF12).

Rats with fasciotomy (WF group $n=16$ ) were divided in two subgroups, eight rats undergoing right testis torsion for six hours, followed by detorsion and testicular decompressive fasciotomy with a tunica vaginalis patch (WF6) and eight rats undergoing right testis torsion for 12 hours, followed by detorsion and testicular decompressive fasciotomy with a tunica vaginalis patch (WF12).

In the sham group ( $\mathrm{S}$ group $\mathrm{n}=8$ ), four rats had their right testis exposed, and pexed; after six hours the right testis was exposed and replaced in the scrotum with orchidopexy. Four rats had the right testis exposed and pexed; after 12 hours the right testis was exposed and replaced in the scrotum with orchidopexy. These animals did not undergo to testicular torsion.

For the control group the left testis of every rat was examined.

The rats were anesthetized with $10 \%$ ketamine hydrochloride $(60 \mathrm{mg} / \mathrm{Kg})$, intramuscularly and xylazine $(10 \mathrm{mg} /$ $\mathrm{Kg}$ ), intramuscularly.

The right testis was exposed through a longitudinal scrotal incision and delivered into the operative field. The gubernaculum was divided, and the spermatic cord was counter rotated 720 degrees. The testis was carefully returned to the scrotum and pexed in position by three 6.0 monofilament sutures, which approximated the tunica albuginea of the lower and two laterals poles of the testis to the dartos. The incision was closed in a single plane with a 5.0 monofilament thread.

At the end of the appropriate interval, the ipsilateral testis was re-exposed surgically. The suture was sectioned and the testis was rotated to its natural position. In the WOF group, the testis was pexed with three 6.0 monofilament sutures, which approximated the tunica albuginea of the lower and two laterals poles of the testis to the dartos. The incision was closed on a single plane with a 5.0 monofilament thread.

After detorsion, a testicular decompressive fasciotomy was performed in the WF group with a longitudinal incision of the tunica albuginea from the upper pole to the lower pole of the testis; then a tunica vaginal flap with an intact vascularized pedicle was harvested. The suture of the flap and the testis fixation were made with a 6.0 monofilament thread using the same aforementioned method. The incision was closed in a single plane with 5.0 monofilament thread. 
The rats were marked with a permanent- pen river system with colors and numbers as in the previous group.

After 42 days, the animals were submitted to bilateral orchiectomy and then euthanized. The testis were photographed, weighed on a digital scale (Adventure OAHUS, AR 3130) and measured with a caliper.

The volume of each testis has been calculated using Cimador et al. ${ }^{8}$ formula:

\section{$0.52 \times$ length $\mathrm{x}$ width $\mathrm{x}$ thickness $\left(\mathrm{cm}^{3}\right)$}

The testes were fixed in Bouin solution for 48 hours, dehydrated in alcohol at $70 \%$ to $100 \%$ progressive concentrations, embedded in paraffin, sectioned, and stained with hematoxylin and eosin (H\&E). The histologic parameters were examined with a light microscopy with x200 and x400 magnifications. The pathologist was blinded to the torsion duration and to the fasciotomy performance status of each sample. Each testis was assigned a 0 to 6 histologic grade based on the following assessment of the seminiferous tubules, as described by Kolbe et al. ${ }^{4}$

Grade 0: Abundant intraluminal spermatozoa. Germinal epithelium composed of normal spermatogenic cells arranged in orderly layers. Normal Sertoli cells. Occasional tubular degeneration noted, usually near the hilum.

Grade 1: Absence of intraluminal spermatozoa. Degeneration and loss of the germinal epithelium with persistence of Sertoli cells. Changes noted in 5\% to $50 \%$ of the crossed- sectional area of the testis.

Grade 2: Grade 1 changes noted in $50 \%$ to $100 \%$ of the crosssectional area of the testis.

Grade 3: Complete loss of germinal epithelium and Sertoli cells. Tubules contained eosinophilic amorphous cellular debris Changes noted in $0 \%$ to $50 \%$ of the cross- sectioned area of the testis.

Grade 4: Grade 3 changes noted in $50 \%$ to $100 \%$ of the crosssectional area of the testis.

Grade 5: Tubular architecture completely obliterated and replaced by histiocytic and lymphocytic infiltrate. Changes noted in $0 \%$ to $50 \%$ of the cross- sectional area of the testes

Grade 6: Grade 5 changes noted in $50 \%$ to $100 \%$ of the crosssectional area of the testes.

We compared the rats' average weight and ages. In order to compare the testicular weights, volumes and the histopathologic degree we applied the non-parametric Mann- Whitney U- test. The differences were considered significant at value $\mathrm{p} \leq 0.05$.

\section{Results}

No rats died or had complications during the observation period. 720 degree torsion was maintained in all of the animals. No differences were found between the rat's average ages and weights in the study subgroups.

When weight, testicular volume and histological grade were compared between the groups with and without fasciotomy and in the six and 12 hours subgroups, there were no differences observed in the six hours subgroup, however differences in all variables were observed in the 12 hours subgroup.

The testicular weight and volume were greater in the animals undergoing testicular detorsion and decompressive fasciotomy as compared to the animals undergoing detorsion without fasciotomy. Furthermore, the histopathologic grade was better in the WF group than in the WOF group (Table 1), (Figures 1 and 2).

TABLE 1 - Comparison of the testicular weight, volume and the histopathological grades of the six and 12 hours subgroups with (WF) and without (WOF) testicular.

\begin{tabular}{cccccc}
\hline Variable & Hours & Groups & $\mathbf{n}$ & Mean \pm SD & p* \\
\hline & 6 & WOF group & 8 & $4.75 \pm 0.89$ & 0.171 \\
HG & & WF group & 8 & $5.25 \pm 1.49$ & \\
$(0-6)$ & & WOF group & 8 & $5.75 \pm 0.71$ & 0.038 \\
& 12 & WF group & 8 & $4.13 \pm 1.89$ & \\
& & WOF group & 8 & $3.21 \pm 0.86$ & 0.916 \\
Weight & 6 & WF group & 8 & $3.24 \pm 1.30$ & \\
$(\mathrm{~g})$ & & WOF group & 8 & $2.14 \pm 0.84$ & 0.046 \\
& 12 & WF group & 8 & $3.54 \pm 1.41$ & \\
& & WOF group & 8 & $0.81 \pm 0.40$ & 0.294 \\
& 6 & WF group & 8 & $0.98 \pm 0.38$ & \\
Volume & & WOF group & 8 & $0.41 \pm 0.34$ & 0.016 \\
$\left(\mathrm{~cm}^{3}\right)$ & 12 & WF group & 8 & $0.94 \pm 0.38$ & \\
& & &
\end{tabular}

$\mathrm{n}=$ number of animals in each group; $\mathrm{SD}=$ Standard Deviation; $\mathrm{HG}=$ Histopathological Grade -Mann-Whitney U’ test. 


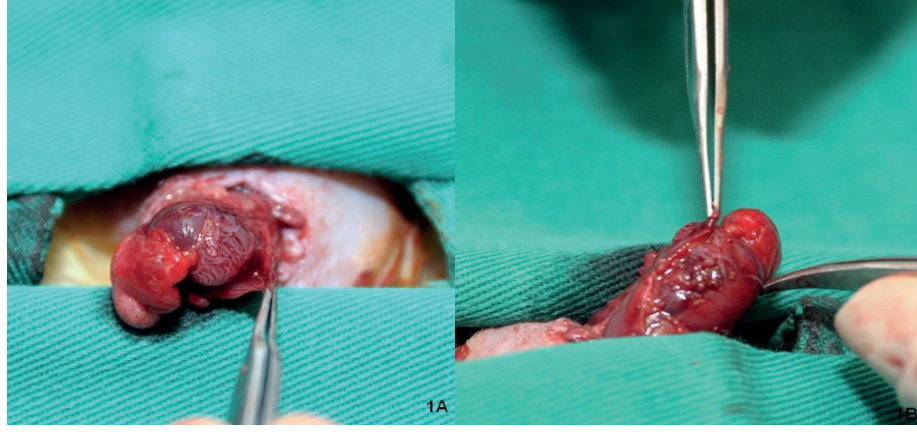

FIGURE 1 - (A) Decompressive fasciotomy testicular in a rat after detorsion. Exposed seminiferous tubules. (B) Rotation flap of the vaginal tunic right testicle on the cruenta area of the rat testicular fasciotomy.

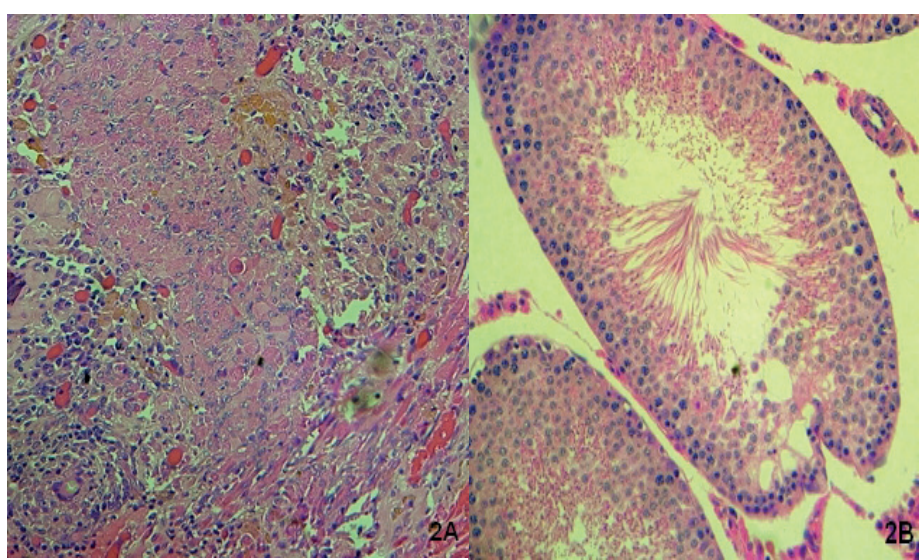

FIGURE2 - (A) Photomicrograph depicting the rat testicular histology of the group undergoing torsion and detorsion for 12 hours without fasciotomy (Grade 6 -right testis). (B) Right rat testis undergoing torsion for 12 hours, detorsion and decompressive fasciotomy. Note the persistent Sertoli cells (Grade1). Magnification x400, H\&E stain. Kolbe's histologic classification.

Testicular weight and testicular volume were greater in the sham group than in the groups without fasciotomy and with fasciotomy. The values were directly proportional to the ischemia duration. The histopathological grade was also superior in the sham group as compared to the other two groups (Tables 2 and 3 ).
TABLE 2 - Comparison of the histopathologic grade (HG), weight and volume of rats' testes in the six and 12 hours subgroups in the group without fasciotomy (WOF) and the sham group.

\begin{tabular}{|c|c|c|c|c|c|}
\hline Variable & Hours & Groups & $\mathbf{n}$ & Mean \pm SD & $\mathbf{p}^{*}$ \\
\hline \multirow{4}{*}{$\begin{array}{l}\text { HG } \\
(0-6)\end{array}$} & \multirow{2}{*}{6} & WOF group & 8 & $4.75 \pm 0.89$ & \multirow{2}{*}{0.171} \\
\hline & & S group & 8 & $1.75 \pm 1.91$ & \\
\hline & \multirow{2}{*}{12} & WOF group & 8 & $5.75 \pm 0.71$ & \multirow{2}{*}{0.038} \\
\hline & & S group & 8 & $1.75 \pm 1.91$ & \\
\hline \multirow{4}{*}{$\begin{array}{l}\text { Weight } \\
\text { (g) }\end{array}$} & \multirow{2}{*}{6} & WOF group & 8 & $3.21 \pm 0.86$ & \multirow{2}{*}{0.916} \\
\hline & & S group & 8 & $4.37 \pm 1.30$ & \\
\hline & \multirow{2}{*}{12} & WOF group & 8 & $2.14 \pm 0.84$ & \multirow{2}{*}{0.046} \\
\hline & & $\mathrm{S}$ group & 8 & $4.37 \pm 1.30$ & \\
\hline \multirow{4}{*}{$\begin{array}{l}\text { Volume } \\
\left(\mathrm{cm}^{3}\right)\end{array}$} & \multirow{2}{*}{6} & WOF group & 8 & $0.81 \pm 0.40$ & \multirow{2}{*}{0.294} \\
\hline & & S group & 8 & $1.55 \pm 0.55$ & \\
\hline & \multirow{2}{*}{12} & WOF group & 8 & $0.41 \pm 0.34$ & \multirow{2}{*}{0.016} \\
\hline & & S group & 8 & $1.55 \pm 0.55$ & \\
\hline
\end{tabular}

$\mathrm{n}=$ number of animals in each group; $\mathrm{SD}=$ Standard Deviation; $\mathrm{HG}=$ Histopathological Grade

-Mann-Whitney U' test.

TABLE 3 - A comparison of the testicular histopathologic grade (HG), weight and volume of rats' testes in the group with fasciotomy (WF) and the sham group.

\begin{tabular}{|c|c|c|c|c|c|}
\hline Variable & Hours & Groups & $\mathbf{n}$ & Mean \pm SD & $\mathrm{p}^{*}$ \\
\hline \multirow{4}{*}{$\begin{array}{l}\text { HG } \\
(0-6)\end{array}$} & \multirow{2}{*}{6} & S group & 8 & $1.75 \pm 1.91$ & \multirow{2}{*}{0.003} \\
\hline & & WOF group & 8 & $4.75 \pm 0.89$ & \\
\hline & \multirow{2}{*}{12} & S group & 8 & $1.75 \pm 1.91$ & \multirow{2}{*}{0.026} \\
\hline & & WOF group & 8 & $5.75 \pm 0.71$ & \\
\hline \multirow{4}{*}{$\begin{array}{l}\text { Weight } \\
(\mathrm{g})\end{array}$} & \multirow{2}{*}{6} & S group & 8 & $4.37 \pm 1.30$ & \multirow{2}{*}{$0.05 \mathrm{~S}$} \\
\hline & & WOF group & 8 & $3.21 \pm 0.86$ & \\
\hline & \multirow{2}{*}{12} & S group & 8 & $4.37 \pm 1.30$ & \multirow{2}{*}{0.208} \\
\hline & & WOF group & 8 & $2.14 \pm 0.84$ & \\
\hline \multirow{4}{*}{$\begin{array}{l}\text { Volume } \\
\left(\mathrm{cm}^{3}\right)\end{array}$} & \multirow{2}{*}{6} & $\mathrm{~S}$ group & 8 & $1.55 \pm 0.55$ & \multirow{2}{*}{0.027} \\
\hline & & WOF group & 8 & $0.81 \pm 0.40$ & \\
\hline & \multirow{2}{*}{12} & S group & 8 & $1.55 \pm 0.55$ & \multirow{2}{*}{0.016} \\
\hline & & WOF group & 8 & $0.41 \pm 0.34$ & \\
\hline
\end{tabular}

$\mathrm{n}=$ number of animals in each group; $\mathrm{SD}=$ Standard Deviation; $\mathrm{HG}=$ Histopathological Grade -Mann-Whitney U' test. 
In comparing the six and 12 hours subgroups of the without fasciotomy (WOF) we observed that the histopathological grade was worse in the 12 hours subgroup. The weight and testicular volume were also smaller in this subgroup.

A comparative analysis between the six and 12 hours subgroups in the group with fasciotomy (WF) indicated no significant difference between the subgroups in any studied variable (Table 4).

TABLE 4-A comparison of the testicular histopathologic grade, weight and volume of the rats' testes in the six and 12 hours subgroups in the groups with and without testicular fasciotomy.

\begin{tabular}{cccccc}
\hline Variable & Groups & Hours & $\mathbf{n}$ & Mean \pm SD & p* \\
\hline & WOF & 6 & 8 & $4.75 \pm 0.89$ & 0.025 \\
HG & group & 12 & 8 & $5.75 \pm 0.71$ & \\
$(0-6)$ & & & & & \\
& WF & 6 & 8 & $5.25 \pm 1.49$ & 0.161 \\
& group & 12 & 8 & $4.13 \pm 1.89$ & \\
& & & & & \\
& WOF & 6 & 8 & $3.21 \pm 0.86$ & 0.046 \\
Weight & group & 12 & 8 & $2.14 \pm 0.84$ & \\
$(\mathrm{~g})$ & & & & & \\
& WF & 6 & 8 & $3.24 \pm 1.30$ & 0.753 \\
& group & 12 & 8 & $3.54 \pm 1.41$ & \\
& & & & & \\
& WOF & 6 & 8 & $0.81 \pm 0.40$ & 0.040 \\
group & 12 & 8 & $0.41 \pm 0.34$ & \\
$\left(\mathrm{~cm}^{3}\right)$ & & & & & 0.636 \\
& WF & 6 & 8 & $0.98 \pm 0.38$ & \\
\hline
\end{tabular}

$\mathrm{n}=$ number of animals in each group; $\mathrm{SD}=$ Standard Deviation; $\mathrm{HG}=$ Histopathological Grade

- Mann-Whitney U’ test.

\section{Discussion}

Several different aspects of experimental spermatic cord torsion have been widely studied, including the effect of ischemia on testicular structure, ischemia/reperfusion, contralateral testis injury, and measures to avoid or reduce these injuries ${ }^{9}$.

Spermatic cord torsion is a major cause of male infertility, and even with appropriate surgical intervention, up to $40 \%$ of testes may be compromised.

Numerous studies have shown a clear association between the torsion duration and the subsequent testicular function, although $27 \%$ of patients with testicular atrophy experienced symptoms for less than five hours before surgical exploration, suggesting that torsion duration is not the only factor to ensure the viability of the testis and spermatogenesis ${ }^{2}$.

Cimador et al. ${ }^{8}$ studied the viability signs of testicular torsion of the spermatic cord and concluded that the most indicative signs were torsion duration, the absence of flow on ultrasound and the absence of bleeding after testicular incision, which had been cited by Arda and $\mathrm{Ozy}^{10}$.

That same year, Ferguson and Brandes ${ }^{11}$ reported using tunica vaginalis to treat firearm-related testicular injury. The patients in Ferguson and Brandes ${ }^{11}$ study had severe testicular damage, with extensive disruption of the albuginea, which prevented primary closure. After debrindige the unviable seminiferous tubules, Ferguson performed a tunica vaginalis graft. All of the patients had favorable outcomes compared to those who received synthetic grafts that developed infection and later required orchiectomy.

In this paper, a free graft was not performed. Instead, a rotation of the tunica vaginalis flap on the surface of the decompressive testicular fasciotomy was performed.

Acute compartment syndrome is a condition in which increased pressure within a limited space compromises the circulation and function of tissues therein, resulting in tissue ischemia and necrosis ${ }^{12}$.

Raised compartimental pressure has been recognized as the final common pathway of a variety of pathologies that lead to microcirculation failure. The failure results in tissue hypoxia and cell death. While commonly seen after trauma, raised intracompartmental pressure may result from either an increase in the tissue volume within a closed fascial compartment or an external force compressing a compartment ${ }^{13}$.

Kutikov et $a l^{3}$ performed a tunica albuginea incision after testicular detorsion to assess bleeding from the testicular tissue. He observed improvement in testicular color after incision. The testicle returned to its original ischemic appearance after the tunica albuginea was closed. Kutikov et al. ${ }^{3}$ hypothesized that compartment syndrome pathophysiology could explain this observation, which was evidenced by using a hand held compartment monitor pressure.

Others studies have demonstrated the benefits of compartment syndrome decompression in human nontesticular pressure $^{12,13}$. So we hypothesized that testicular fasciotomy might be reflected on macroscopic and microscopic testicular aspects.

Kolbe et $a l{ }^{4}$ reported no statiscally significant testicular damage from "testicular capsulotomy" in Sprague- Dawley rats as assessed by testicular histological examinations. The results 
were inconclusive because of a large variability in the histologic response to torsion, regardless of whether the tunica albuginea was incised.

Post-torsion, the following parameters had histology scores that were dependent on the torsion duration: loss of spermatozoa and spermatids, degeneration of germ cells layers, disarray of germ cells layers, rupture of tubules, edema and hemorrhage ${ }^{14}$.

We used Kolbe's classification to describe these changes in a sequential manner with optical microscopy. The group with a longer ischemic duration (12 hours) and without fasciotomy showed the worst classification level. Those rats presented a tubular architecture that was completely obliterated and replaced with a lymphocytic and histiocytic infiltrate.

The animals from the 12 hours spermatic cord torsion subgroup of the group that underwent fasciotomy and decompression with flap rotation of the tunica vaginalis testis had heavier weights, larger volumes and superior histopathological grade classifications as compared to the 12 hours subgroup without fasciotomy.

These results confirm the role played by compartmental syndrome alterations in the pathophysiology of testicular torsion of the spermatic cord and the need for decompression. The contralateral testes were always normal, regardless of the duration of torsion or receipt of fasciotomy. This result is consistent with the data from previous studies ${ }^{15,16}$.

Recently Moritoki et al. ${ }^{17}$ published interesting animal data linking intratesticular pressure with histological changes. Moritoki's study suggests that intratesticular pressure can be used as an index for determining whether the affected testis will cause significant damage to spermatogenesis. However his assessment and analysis did not aim at a therapeutic strategy, but more toward a diagnostic maneuver that could help determine testicles at higher risk of irreversible ischemia and more likely to benefit from removal.

Currently clinical data suggest that post-detorsion compartment syndrome may be amenable to decompression by generous incision of testicular tunica albuginea. Figueroa et $a l{ }^{18}$ instituted tunica albuginea incision with tunica vaginalis flap coverage as an alternative in cases which the torsed testes continued to appear ischemic after detorsion. Testicular volume and parenchymal blood flow as measured by Doppler scrotal ultrasound were analyzed. They did not study the histopathological degree. Despite the limited numbers they had a good rate of testicular salvage and a decrease in the number of orchiectomies.

Our findings contribute to the potential value of this technique.

There are important limitations of our analysis that should be taken into account. The testicular weight and volume have a limited correlation with future hormone production or fertility. Nevertheless, a statistically clear correlation was observed between the testicular fasciotomy and testicular weight, volume and histopathologic grade.

Our study appears to be the first experimental study to demonstrate the correlation between testicular fasciotomy and histopathologic degree.

It provides promising data that give credit to this procedure and stronger argument for further studies.

\section{Conclusions}

Decompressive testicular fasciotomy caused testicular macroscopic changes (increased weight and testicular volume) and histopathologically beneficial changes in the group of animals that received torsion for 12 hours, followed by detorsion and fasciotomy compared with the group receiving torsion for 12 hours and detorsion without fasciotomy. No impairment was found in the macroscopic or microscopic contralateral testicular torsion.

\section{References}

1. Williason RC. Torsion of the testis and allied conditions. Br J Surg. 1976;63(6):465-6

2. Sessions AE, Rabinowitz R, Hulbert WC, Goldstein MM, Mevorach RA. Testicular torsion: direction, degree, duration and disinformation. J Urol. 2003;169(2):663-5.

3. Kutikov A, Casale P, White AM, Meyer WA, Chang A, Gozalbez R, Canning DA. Testicular compartment syndrome: a new approach to conceptualizing and managing testicular torsion. Urology. 2008;72(4):786-9.

4. Kolbe A, Sunc CC, Hill JL. Unpredictability of capsulotomy in testicular torsion. J Pediatr Surg. 1987;22:1105-9.

5. Yurtçu M, Abasiyank A, Biçer S, Avunduk MA. Efficacy of antioxidant treatment in the prevention of testicular atrophy in experimental testicular torsion. J Pediatr Surg. 2009;44(9):1754-8.

6. Payabvash S, Kiumehu S, Tavangar SM, Dehpour AR. Ethyl pyruvate reduces germ cell-specific apoptosis and oxidative stress in rat model of testicular torsion/ detorsion. J Pediatr Surg. 2008;43(4):705-12.

7. Guimarães SB, Aragão AA, Santos JM, Kimura OS, Barbosa $\mathrm{PH}$, Vasconcelos PR. Oxidative stress induced by torsion of the spermatic cord in young rats. Acta Cir Bras. 2007;22(1):30-3.

8. Cimador M, Dipace MR, Castagnetti M, Degrazia E. Predictors of testicular viability in testicular torsion. J Pediatr Urol. 2007;3(5):38790.

9. Romero FR, Gomes RP, Lorenzini F, Edrmann TR, Tambara Filho R. Ipsilateral testicular necrosis and atrophy after 1080 degree torsion of the spermatic cord in rats. Acta Cir Bras. 2009;24(2):118 23.

10. Arda IS, Ozy IA. Testicular tissue bleeding as an indicator of gonadal 
salvageability in testicular torsion surgery. BJU Int. 2001;87(1):8992.

11. Ferguson GG, Brandes SB. Gunshot wound injury of the testis: the use of tunica vaginalis and polytetrafluoroethylene grafts for reconstruction. J Urol. 2007;178 (6):2462-5.

12. Tollens $\mathrm{T}$, Janzing $\mathrm{H}$, Broos $\mathrm{P}$. The pathophysiology of the acute compartment syndrome. Acta Chir Belg. 1998;98(4):171-5.

13. Mars M, Hadley GP. Raised intracompartmental pressure and compartment syndromes. Injury. 1998;29(6):403-11.

14. Consentino MJ, Nishida M, Rabinowitz R, Cokket AT. Histopathology of prepubertal rat testis subjected to various durations of spermatic cord torsion. J Androl. 1986;7(1):23-31

15. Turner TT. Acute experimental testicular torsion. No effect on the contralateral testis. J Androl. 1985;6(1):65-72.

16. Turner TT, Brown KJ. Spermatic cord torsion loss of spermatogenesis despite return of blood flow. Biol Reprod. 1993;49(2):401-7.

17. Moritoki Y, Kojima Y, Mizuno K, Kamisawa H, Kohri K, Hayashi Y. Intratesticular pressure after testicular torsion as a predictor of subsequent spermatogenesis: a rat model. BJU Int. 2012;109(3):46670 .

18. Figueroa V, Pippi Salle JL, Braga LH, Romao R, Koyle Ma, Bagli DJ, Lorenzo AJ. Comparative analysis of detorsion alone versus detorsion and tunica albuginea decompression (fasciotomy) with tunica vaginalis flap coverage in the surgical management of prolonged testicular ischemia. J Urol. 2012;188(4 Suppl):1417-22.

\section{Correspondence:}

Isabela Passos Pereira Quintaes

Rua Maranhão, 95/903

29101-340 Vila Velha - ES Brasil

Tel.: (55 27)3349-0142 / 9982-7280

isabelappquintaes@hotmail.com

Received: February 14, 2013

Review: April 16, 2013

Accepted: May 13, 2013

Conflict of interest: none

Financial source: none

${ }^{1}$ Research performed at Laboratory of Division of Surgical Principles, Surgery Department, School of Science, Santa Casa de Misericordia de Vitoria (EMESCAM), Espirito Santo, Brazil. 